EDITORIAL

\title{
What is research?
}

\section{Dong-Wook Song ${ }^{1}$}

Published online: 16 December 2021

○ World Maritime University 2021

There is nothing so practical as a good theory.

Kurt Lewin (1890-1947)

One of the duties to be conducted by an editor-in-chief is to make an editorial decision by accepting, requesting for revision(s) or rejecting a submitted manuscript after a round of reviewing processes or even before putting it into the reviewing procedure: that is desk rejection. See more about the decision-making process in the previous editorial (Song 2020b). Authors of rejected manuscripts are likely to think of why their works are refused to be published at a peer-reviewed journal. In this editorial, your editor-in-chief attempts to express an overview of his perspective and/or philosophy on the related matter.

\section{Research in definition}

In his well-known book What is history?, Carr (1961) defines the history as a neverending conversation between the past and the present. Similarly, the authors of The Craft of Research put their definition of the research as a conversation by helping you (as a researcher) and your community (i.e. learned societies) free us (i.e. general public) from ignorance, prejudice and the half-baked ideas that so many charlatans try to impose on us (Booth et al., p. 11). Furthermore, Huff (2009) starts her well-articulated book Designing Research for Publication with the chapter headed 'Finding the Right Conversation'. The chapter is composed of such sub-headings as 'scholarship as a social, sensemaking activity', 'identifying scholarly conversations', 'choosing your conversation', 'developing a scholarly identity that informs scholarly choices' and 'balancing attraction, agreement and disagreement'.

All the three books, being widely recognised and used for educating learned people like you, do commonly mention the term 'conversation' in a way to elucidating research. When googling further for more, you will find the following definition given by the Western Sydney University (2021):

Dong-Wook Song

joma@wmu.se

1 World Maritime University, Malmö, Sweden 
"Research is defined as the creation of new knowledge and/or the use of existing knowledge in a new and creative way so as to generate new concepts, methodologies and understandings. This could include synthesis and analysis of previous research to the extent that it leads to new and creative outcomes."

Putting all those explications into a single frame, one could interpret that the research (more preciously, academic or scientific research) has to do with (i) linking (that is a 'conversation') what has been done (the past) with what has to be done (the present and/or future) in a way to generate new knowledge and (ii) objectifying what you are doing in a way to contribute to your chosen field (or community).

The former is named a literature review, while the latter a methodology. While acknowledging that these two activities are deemed to need further discussion in a detailed manner, ${ }^{1}$ the current editorial aims to proceed towards the definition and types of research in a context of maritime studies as an applied science.

\section{Applied research in definition}

In a simple but distinctive manner, Booth et al. (2016, pp. 51-65) define pure (or basic) and applied research as "We call pure research when it addresses a conceptual problem that does not bear directly on any practical situation in the world..... [we] call applied research when it addresses a conceptual problem that does have practical consequences..... '[what] we should think' is concerned with the conceptual problem, while 'what we should $d o$ ' is with the practical problem." [emphases inserted].

On the same matter, Flexner (1939) went even further by quoting the Nobel laureate George Porter saying the two types as applied and 'not-yet-applied' research: the latter being regarded as pure research (or blue sky research). In his context, findings from pure research are treated by general public as 'useless knowledge' until they become applied for human's wellbeing (that is the useless knowledge has been eventually transformed into being useful). He did, however, make an emphasis on the fact that pure scientists, like Albert Einstein, had not considered the practicality nor applicability of their theory when launching their exploration; they did simply out of curiosities. Applied scientists are those who see a potential by examining theories developed by pure scientists and apply them to human's welfares; those who developed GPS from the Einstein's theory are those categorised ones in this context.

Turning on to the domain of social sciences, we are still able to observe the similar trajectory that has been developed. For example, Kurt Lewin (1890-1947), whose works in the field of applied psychology or organisation and management sciences are widely cited, did firmly claim that those working in practice-geared disciplines are to be a practical theorist. This assertion is vindicated by his most frequently cited sentence as quoted in the beginning of this editorial. His stand on the

1 These issues will be also discussed in the forthcoming editorials in due course. 
nature of applied research does clearly indicate that theories and/or concepts are a starting point for applied scientists to commence their journey of investigation.

\section{Types of research}

Having the aforementioned points in mind, this editorial makes an effort to classify the types of applied research using the following diagram. ${ }^{2}$ In a simple way, we are to generate a concept on our way towards theory by carefully observing the practice: so-called theory-building. Consequently, the developed concepts/theories are to be tested in an incremental manner to better reflect the practice: named 'theory-testing'. In this sense, we could illustrate the related mechanism between theory on one side and practice on the other in a either direct or indirect format (expressed in a dotted line in the figure). In other words, some theories remain in a stage where they have not yet applied or related to the practice, while others are practically attached to the world.

The spectrum spread across the line between theory and practice could be approximately pointed into four spots (I to IV) in terms of nature of applied research.

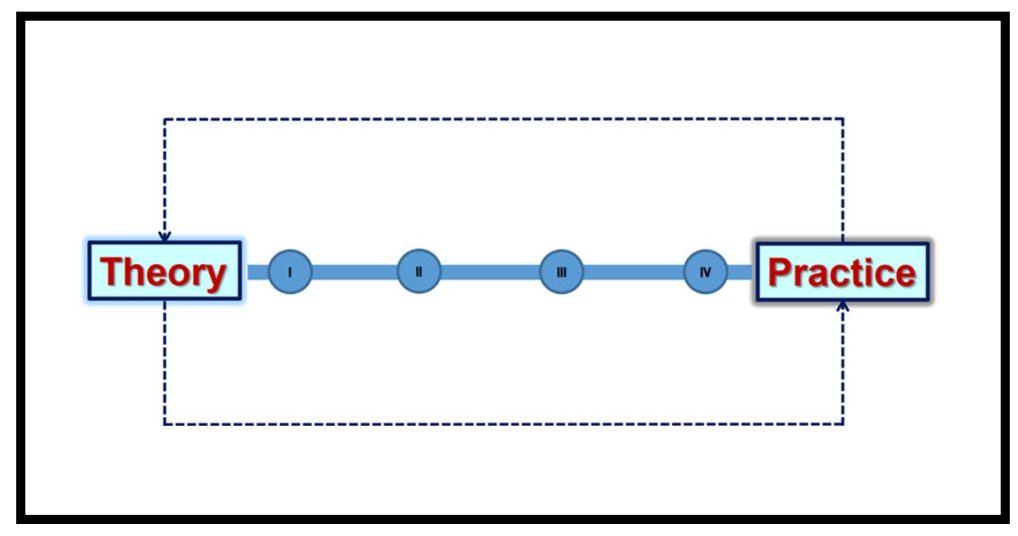

Type I is a theory-focused research, while Type IV is a practice-driven one. Most of the applied research could fall into somewhere between the two-Type II or Type III. Specifically speaking, the editorial defines the Type I to be 'close-to-blue-skyresearch' as it conducts for the sake of developing, enhancing or improving related concept/theory. The Type II could be the one that performs theory-dominated and practice-considered research. Its example could include, amongst others, those researches in responding to the call for applications commissioned by research

\footnotetext{
2 The editorial does fully acknowledge and appreciate that expressing the complexity involved with dynamism between theory and practice as a dichotomised form would be too simplistic to be convincing. The current effort is, however, made to convey the editor's perspective and philosophy towards maritime studies (as a branch of applied research) as simplest as possible.
} 
councils, non-profit-making foundations or similar institutes whose interests are in making the world a better place by enhancing knowledge beneficial to the wide public. Research is considered principally as public goods under this category. The editorial names it 'responsive research'. The Type III could be the one that conducts the research having specific beneficiaries in mind from the beginning. The editorial calls the Type III as 'contracted research' including consultancies. Finally, the Type IV would be the in-house research executed exclusively for their own interest, the outputs of which are often produced in a form of company or organisation reports. Some of those reports are at times used either partially or fully for the purpose of promoting companies/organisations in question. This Type IV can be termed 'in-house research'.

\section{Expected types of papers}

Having once again defined the discipline of maritime studies in a broad sense (see more at Song 2020a) as an applied science, the WMU Journal of Maritime Affairs (JOMA) as a peer-reviewed 'academic' dissemination outlet would welcome the Type I and Type II papers with the expectations that the Typed-II-papers could be majority. At the same time, however, JOMA as an 'industry'-geared outlet would also welcome the Type III papers, subject to those works to be objectified ${ }^{3}$ prior to submission to the journal for consideration. The Typed-IV-papers could be treated as a special case under the title of views from industrial professionals: that is the issues of contemporary interest as indicated in the editorial (Song 2020a). Those authoritative voices from the industry would be 'invited' to express their views for the case of this Type IV of papers.

\section{Final words}

Assuming that most of the present and prospective authors, readers, reviewers or other stakeholders for JOMA are an 'academic' applied researcher, the editorial would like to summarise what has been discussed in the section by quoting the following point made by Kurt Lewin (1890-1947) who claimed himself as a practical theorist.

"Theory should fulfil two main functions: first, it should account for what is known; second, it should point out the way to new knowledge. .... [research] should therefore be undertaken with the purpose of testing theoretical concepts, instead of merely collecting and analysing elemental facts or classifying behaviour statistically." (Marrow 1969, p. 30)

\footnotetext{
3 The subject of 'how to objectify' will be another topic to be dealt with at the forthcoming editorial in due time.
} 
Having attempted to discuss what might be sensitive, subjective or perspectivebiased to some, as usual, your editor-in-chief looks forward to receiving comments and feedbacks from you as a current and future contributor to the discipline of maritime studies in general and JOMA in specific. We could then collectively develop our beloved maritime communities as a backbone to the global economies. Please drop him an email whenever you feel it could be helpful and useful to the common good of the journal and/or maritime communities.

\author{
Dong-Wook Song \\ Editor-in-Chief \\ joma@wmu.se
}

\title{
References
}

Booth W, Colomb G, Williams J, Bizup J, FitzGerald W (2016) The craft of research, 4th edn. University of Chicago Press, London

Carr E (1961[2001]) What is history? Palgrave Macmillan, London

Flexner A (1939[2017]) The usefulness of useless knowledge. Princeton University Press, Oxford

Huff A (2009) Designing research for publication. Sage Publications, London

Marrow A (1969) The practical theorist: the life and work of Kurt Lewin. Basic Books, London

Song D-W (2020a) Editorial: looking back for the future. WMU J Marit Aff 19(1):1-3

Song D-W (2020b) Editorial: decision-making process for journal articles. WMU J Marit Aff 19(2):159-162

Western Sydney University (2021) Definition of Research. https://www.westernsydney.edu.au/resea rch/researchers/preparing_a_grant_application/dest_definition_of_research. Accessed on 15th November

Publisher's note Springer Nature remains neutral with regard to jurisdictional claims in published maps and institutional affiliations. 